\title{
Patent foramen ovale causing position-dependent shunting in a patient, when laying down her corset
}

\author{
J.C. Grutters*, J.M. ten Berg", J. van der Zeijden", W. Jaarsma\#, J.M.P.G. Ernst", \\ C.J.J. Westermann*
}

Patent foramen ovale causing position-dependent shunting in a patient, when laying down her corset. L.C. Grutters, J.M. ten Berg, J. van der Zeijden, W. Jaarsma, J.M.P.G. Ernst, C.J.J. Westermann. (C) ERS Journals Ltd 2001.

ABSTRACT: A 75-yr-old female presented with platypnoea and orthodeoxia, shortly after laying down an old and pinching corset. The injection of activated Haemaccel in the right cubital vene during transoesophageal echocardiography, in the upright position, revealed a direct blood flow from the superior caval vein at a patent foremen ovale, consequently opening it and causing a large right-to-left shunt which was calculated at $28.5 \%$. In the supine position there was only a minimal opening of the patent foremen ovale with a calculated right-to-left shunt of $9.5 \%$. The patent foremen ovale was successfully closed percutaneously with a CardioSEAL ${ }^{\mathrm{TM}}$. Eur Respir J 2001; 18: 731-733.

\begin{abstract}
Depts of *Pulmonology and ${ }^{\#}$ Cardiology, St. Antonius Hospital Nieuwegein, and "Dept of Pulmonology, Overvecht Hospital Utrecht, the Netherlands.
\end{abstract}

Correspondence: C.J.J. Westermann, Dept of Pulmonology, Sint Antonius Hospital, PO Box 2500, 3430 EM Nieuwegein, the Netherlands. Fax: 313060952001

\section{Keywords: Orthodeoxia} patent foramen ovale percutaneous closure position-dependent right-to-left shunt

Received: January 42001

Accepted after revision May 252001
Right-to-left shunting through a patent foremen ovale (PFO) is mostly caused by increased right arterial pressure (massive pulmonary embolism or primary pulmonary hypertension). Another major cause is an abnormal anatomical relationship with a change in the blood flow from the inferior caval vein directed to the PFO. This condition may be seen after pneumonectomy [1].

In this study the very unusual presentation of platypnoea (breathlessness in the upright position) and orthodeoxia (arterial desaturation in the upright position) in a 75-yr-old female after taking off a corset is described.

\section{Case report}

A 75-yr-old female patient was referred to the authors' hospital (St Antonius Hospital) for further analysis of severe shortness of breath and desaturation in the upright position and the suspicion of a right-toleft shunt. Symptoms preventing the patient from performing any physical activity had started shortly after laying down an old and pinching corset. The medical history revealed an ischaemic cerebrovascular accident with complete recovery and two transient ischaemic attacks. There was no history of other cardiopulmonary disease and the patient had never smoked.

At first presentation, the patient showed no signs of shortness of breath when lying in bed. In the upright position, however, severe breathlessness occurred and central cyanosis became obvious. Sitting or lying down made her regain her breath and cyanosis disappeared. Examination of the heart and lungs was normal; there were no signs of congestive heart failure. Further physical examination revealed no abnormalities, except for a thoracic kyphosis. Routine laboratory tests were normal. A chest radiograph demonstrated normal lung fields and heart figure, but showed a small thoracic stomach. Pulmonary function tests revealed no evidence of obstructive or restrictive disease and the diffusing capacity for carbon monoxide was normal.

Arterial blood gas analysis showed an oxygen tension in arterial blood $\left(\mathrm{Pa}_{\mathrm{a}} \mathrm{O}_{2}\right)$ of $12.1 \mathrm{kPa}$ in the supine position, and a $\mathrm{Pa}, \mathrm{O}_{2}$ of $7.2 \mathrm{kPa}$ in the upright position. After breathing pure oxygen for $30 \mathrm{~min}$, the right-to-left shunt was calculated using the classical equation and assuming an arteriovenous difference in the oxygen content of $5 \mathrm{~mL} \cdot 100 \mathrm{~mL}^{-1}$ [2]. The rightto-left shunt was $9.5 \%, 9.0 \%$ and $28.5 \%$ in the supine, sitting and upright position, respectively.

Supine transthoracic echocardiography (ECHO) and pulmonary angiography showed normally sized and contracting heart chambers, normal heart valves, no septum defects, and no pulmonary embolism or arteriovenous malformations. Also, no elevation of the right heart and pulmonary pressures was found.

On suspicion of positionally induced shunting in the heart, a transoesophageal ECHO was performed in different positions. After the injection of activated 
Haemaccel into the right cubital vene, a very small right-to-left shunting across the atrial septum, i.e. a PFO, was seen in the supine position (fig. 1a). In the upright position, however, there was a large increase in shunting (fig. 1b). This was due to a direct blood flow from the superior caval vein to the PFO, consequently opening it.

Because of the relationship between the onset of symptoms and the laying down of the old corset by the patient, a new corset was made. Remarkably, the wearing of this corset prevented the desaturation in the upright position. However, the patient preferred a definitive solution. Moreover, the three neurological events in the past could have been caused by paradoxical embolism through the PFO [3]. Therefore, the PFO was successfully closed percutaneously with the placement of a CardioSEAL ${ }^{\mathrm{TM}}$ (figs. 1c and $\mathrm{d}$ ).

After the closure of the PFO, the platypnoea and orthodeoxia were no longer present. The patient felt very well and was able to return to normal everyday physical activities in the upright position. The rightto-left shunt after the closure of the PFO was calculated at $4.5 \%$ in both the supine and in the upright position.

\section{Discussion}

This case study documents a 75-yr-old female patient presenting with platypnoea and orthodeoxia caused by a large increase of right-to-left shunting across a PFO in the upright position. The right atrial pressure as well as other known causes for right-to-left shunting across a PFO were normal, e.g. pneumonectomy, was absent.

Right-to-left shunting across a PFO in the absence of lung and heart disease has been reported. Recently, FALLER et al. [4] described a right-to-left shunt through a PFO in association with both an atrial septum aneurysm and a thoracic aorta aneurysm. SORRENTINO et al. [5] described a case of platypnoea and orthodeoxia caused by right-to-left shunting across a PFO in a patient with normal pulmonary artery pressure and normal heart function. They speculated that a different anatomical relationship of
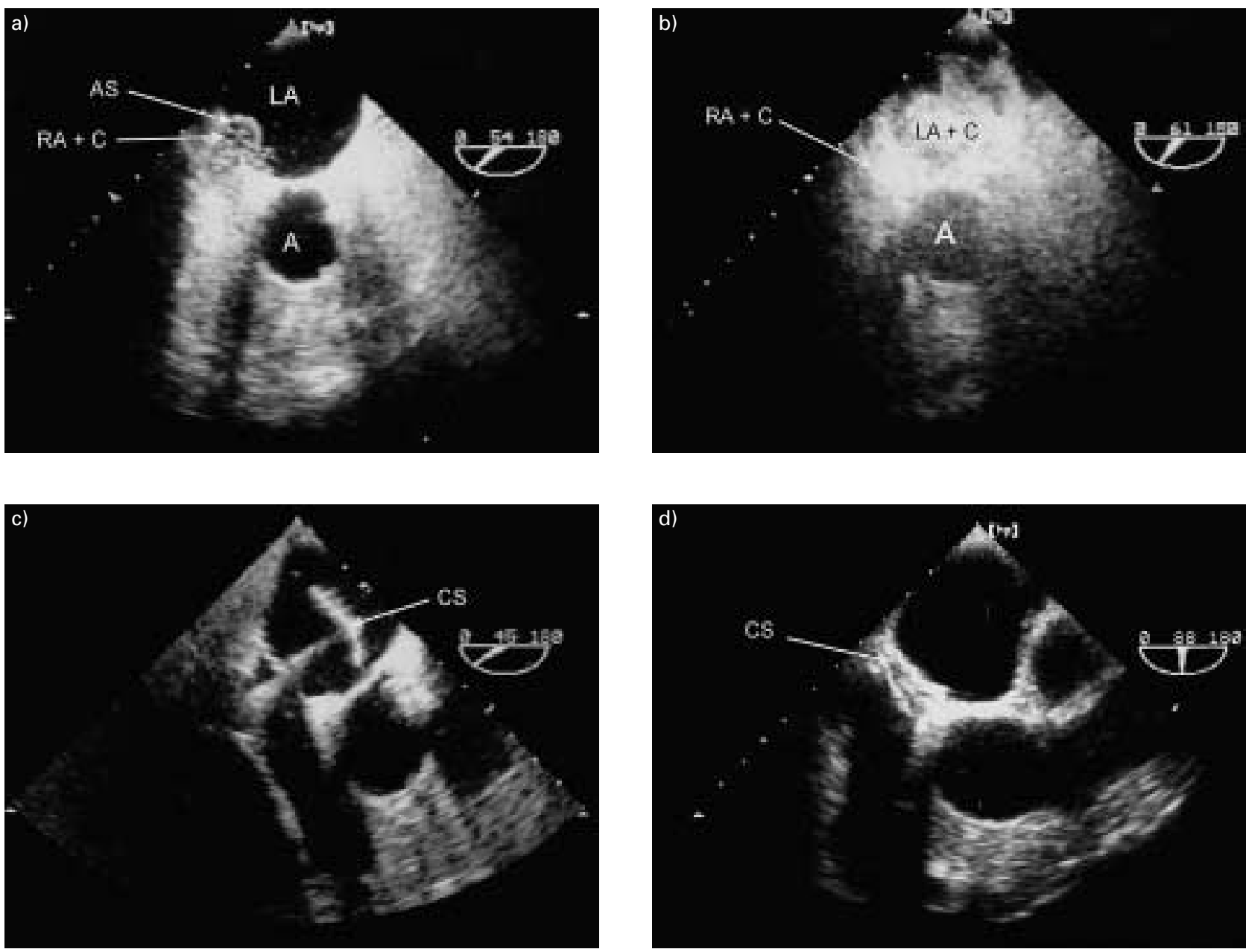

Fig. 1.-a) Transoesophageal contrast echocardiogram in the supine position showing a very small right-to-left shunting across the patent foremen ovale (PFO). b) Large increase of the right-to-left shunting in the upright position. c) Positioning of a CardioSEAL ${ }^{\text {TM }}$ across the PFO. d) Successfully closed PFO with a CardioSEAL ${ }^{\mathrm{TM}}$. RA+C: right atrium filled with contrast; AS: atrial septum; LA: left atrium; A: aorta; LA $+\mathrm{C}$ : left atrium filled with contrast; CS: CardioSEAL ${ }^{\mathrm{TM}}$. 
the inferior caval vein to the PFO in the supine versus the upright position was responsible for the shunt. In the present patient a transoesophageal contrast ECHO visualized a change of blood flow direction from the superior caval vein to the PFO in the supine versus the upright position. To the best of the authors' knowledge this is the first case in the medical literature, where the superior caval vein is involved. It is obvious that the contrast material has to be injected in a peripheral vein draining on the involved caval vein, when one tries to visualize the shunting with contrast echography. The symptoms started when the patient lay down an old corset, and disappeared when it was substituted with a new one. Without the corset there was a prolapse of the abdominal wall, which might have caused a decrease in the intra-abdominal pressure and subsequently lowering of the diaphragm with a change in the position of the heart. It is therefore, speculated that a gravity-induced change in the anatomical relationship of the heart to the superior caval vein was responsible for the documented change in blood flow direction to the PFO in the supine versus the upright position. It is also conceivable that the thoracic kyphosis and the thoracic stomach have contributed to a small but pathophysiologically relevant change in the anatomical relationship of the heart to the caval vein in this patient.
The new corset prevented desaturation in the upright position. However, because of the neurological events in the past, a definitive closure of the patent foramen ovale was preferred. This was successfully achieved through placement of a CardioSEAL ${ }^{\mathrm{TM}}$ with a percutaneous catheter technique, which is presently the treatment of choice for this disease.

\section{References}

1. Rossum van P, Plokker HWM, Ascoop CAPL. Breathlessness and hypoxaemia in the upright position after right pneumonectomy. Eur Heart $J$ 1988; 9: 1230-1233.

2. Chiang ST. A nomogram for venous shunt (QS/QT) calculation. Thorax 1968; 23: 563-565.

3. Lechat P, Mas JL, Lascault G, et al. Prevalence of patent foremen ovale in patients with stroke. $N$ Engl $J$ Med 1988; 318: 1148-1152.

4. Faller M, Kessler R, Chaouat A, Ehrhart M, Petit H, Weitzenblum E. Platypnea-orthodeoxia syndrome related to an aortic aneurysm combined with an aneurysm of the atrial septum. Chest 2000; 118: 553557.

5. Sorrentino M, Resnekov L. Patent foremen ovale associated with platypnea and orthodeoxia. Chest 1991; 100: 1157-1158. 